\title{
Genetic association of liver $X$ receptor beta rs 2695121 polymorphism with obesity-related traits in a northeastern Iranian population
}

\author{
Hassan Mehrad-Majd ${ }^{1}$, Majid Ghayour-Mobarhan², Mohamad-Reza Zali ${ }^{3}$
}

${ }^{1}$ Ph.D. of Molecular Medicine, Assistant Professor, Clinical Research Unit, Mashhad University of Medical Sciences, Mashhad, Iran

${ }^{2}$ M.D., Ph.D. of Nutrition, Professor, Biochemistry of Nutrition Research Center, Faculty of Medicine, Mashhad University of Medical Sciences, Mashhad, Iran

${ }^{3}$ M.D. in Gastroenterology, Professor, Research Institute for Gastroenterology and Liver Diseases, Shahid Beheshti University of Medical Sciences, Tehran, Iran

\section{Type of article: Original}

\begin{abstract}
Background: Liver X receptor Beta (LXR $\beta$ ), located in an obesity susceptible region, has been shown to be involved in the metabolism of lipid and carbohydrates. Previous human genetic studies have suggested genetic variability of LXR $\beta$ could be associated with human obesity. Therefore, we hypothesized that LXR $\beta$ gene rs2695121 polymorphism may be associated with the risk of obesity in a northeastern Iranian population.

Methods: A TaqMan allelic discrimination assay was used to genotype LXR $\beta$ rs 2695121 polymorphism in this cross-sectional study of 168 obese, 209 overweight and 76 normal-weight subjects recruited from Mashhad city in Iran. Logistic regression analyses were used to analyze alleles and genotypes distribution. Anthropometrics and clinical variables among different genotype carriers were compared by univariate analyses. All statistical analysis was performed using SPSS v.16.0.

Results: Allelic and genotypic associations with obesity were not significant for the rs2695121 variant even after adjustment for age and gender $(\mathrm{OR}=1.17,95 \% \mathrm{CI}=0.46-2.91), \mathrm{p}=0.586)$. Moreover, haplotype analysis using data from the other variant ( $r 17373080)$ of LXR $\beta$ revealed no significant association $(\mathrm{p}=0.88)$. However, among the clinical and metabolic parameters tested, systolic and diastolic blood pressures were found nominally associated with the genotype $\mathrm{CT}$ ( $\mathrm{p}=0.031$ and $\mathrm{p}=0.017$ respectively).

Conclusion: This study failed to demonstrate any association between the rs 2695121 variant of LXR $\beta$ and obesity neither alone nor when considered with rs 17373080 . However, its association with blood pressure may influence one's susceptibility to obesity, supporting further studies in a larger population.

Keywords: Liver X receptor- $\beta$; Obesity; Polymorphism; rs2695121
\end{abstract}

\section{Introduction}

Liver $X$ receptor beta $(\operatorname{LXR} \beta)$ is a member of the nuclear hormone receptor superfamily which modulates transcription of many target genes involved in cholesterol, lipid and carbohydrate metabolism (1-3). This liganddependent transcription factor is encoded by the nuclear receptor 1 type H2 (NR1H2) gene located on chromosome 19 and is ubiquitously expressed at moderate to high levels in almost all tissues (4). The transcriptional activity of LXR $\beta$ is depended on the exposure of oxidized cholesterol and subsequent heterodimerization with the retinoid X receptor (RXR). Activated LXR-RXR heterodimers promote adipogenesis and lipid accumulation in adipocytes by transcriptional regulation of sterol regulatory binding transcription factor 1 (SREBP1C), the master regulator of TG synthesis, and several target genes including FAS and stearoyl-CoA desaturase 1 in the SREBP1C pathway (5-8).

\section{Corresponding author:}

Hassan Mehrad-Majd, Clinical Research Unit, Ghaem Hospital, Faculty of Medicine, Mashhad University of Medical Sciences, Mashhad, Iran, P.O. Box: 9177948564.

Tel:+98.5138828573, Fax:+98.5138828574, Email: Mehradmajd.h@gmail.com

Received: October 12, 2017, Accepted: January 02, 2018, Published: January 2018

iThenticate screening: December 24, 2017, English editing: January 14, 2018, Quality control: January 15, 2018

This article has been reviewed / commented by five experts

(C) 2018 The Authors. This is an open access article under the terms of the Creative Commons Attribution-NonCommercialNoDerivs License, which permits use and distribution in any medium, provided the original work is properly cited, the use is non-commercial and no modifications or adaptations are made. 
The lipogenic actions of LXRs have presented them as potential pharmaceutical targets for the treatment of metabolic disorders such as diabetes, metabolic syndrome, obesity, and atherosclerosis (9). Targeted disruption (knockout) of the LXR $\beta$ gene in mice have revealed a strong association with defects in the cardiovascular system, homeostasis and metabolism and the nervous system (10). Based on having an important role in regulating the lipid and carbohydrate metabolism, genetic variations in LXR $\beta$ may contribute in mediating susceptibility to obesity and modulating serum lipids and glucose levels. One of the common variations within the NR1H2 gene is rs2695121, which is identified by $\mathrm{C}$ to $\mathrm{T}$ substitution in intron 2. This SNP was associated with several metabolic-related disorders including high blood pressure, metabolic syndrome, type 2 diabetes and also preeclampsia (11-13). A 2006 study by Dahlman reported evidence of the association between LXR $\beta$ rs 2695121 polymorphism and obesity phenotypes (13). Whereas, other subsequent reports have been inconsistent (14). However, no reported data exists for the association of this SNP with the risk of obesity and related metabolic traits in an Iranian population. Based on the proposed involvement of LXR $\beta$ in the regulation of lipid and carbohydrate homeostasis, the present crosssectional study was designed to assess the potential association of LXR $\beta$ rs2695121 variant with obesity and related metabolic traits in a northeastern Iranian population.

\section{Material and Methods}

\subsection{Subjects}

In this cross-sectional study, a total of 453 genetically unrelated adult subjects of both genders, ranging from 18 to 60 years of age, were enrolled from our previous study in which the relationship of two LXR $\alpha$ SNPs with obesity was investigated on individuals who were randomly selected from participants of a cohort study of metabolic syndrome and cardiovascular disease risk factors performed in Mashhad as a second largest city in Iran (15). The World Health Organization-body mass index (WHO-BMI) was calculated as a weight to height ratio $\left(\mathrm{kg} / \mathrm{m}^{2}\right)$, and a BMI of 18.5-24.99, 25-29.99 and $\geq 30 \mathrm{~kg} / \mathrm{m}^{2}$ were taken as cut-off values defining normal weight, overweight and obesity, respectively. With this in mind, all subjects were classified into three groups: 209 subjects as overweight, 168 subjects as obese, and 76 healthy individuals as normal weight. Before participating voluntarily in research work, informed written consent was obtained from all participants. After that, a complete physical assessment and anthropometric measurements were performed by trained health workers. Blood samples were drowned after a fasting period, and data on age, sex, geographical birthplace, ethnicity, past medical and family history, and dietary habits were collected. All subjects with a history of stroke, MI (Myocardial infarction), endocrinological abnormalities, diabetes mellitus, alcohol consumption, heart, liver and/or renal disease, or those who were under high blood pressure medication and lipid or glucose lowering treatment were excluded from the study. This research project was approved by the Ethical Committee of the Shahid Beheshti University of Medical Sciences (SBUMS: Research Project No. 648).

\subsection{Anthropometric and Biochemical measurements}

Anthropometric and clinical measurements were measured according to international standard procedures as described in details in our previous studies $(11,15,16)$. In brief, all parameters including height, weight, waist circumference (WC), hip circumference (HC), waist/hip ratio, systolic blood pressure (SBP) and diastolic blood pressure (DBP), total cholesterol (TC), high- density lipoprotein cholesterol (HDL-C), low-density lipoprotein cholesterol (LDL-C), triglycerides (TG), fasting blood glucose (FBG) and serum C-reactive protein (CRP) were measured.

\subsection{Genotyping}

Genomic DNA was isolated from the peripheral blood sample with a FlexiGene DNA Kit (Qiagen) in accordance with the manufacturer's instructions. Genotyping of single nucleotide polymorphisms (SNPs) was performed by allelic discrimination assays using TaqMan probes (C_16059177_10; Applied Biosystems, USA). Allelic discrimination was performed on Applied Biosystems 7500 real-time PCR System. The following conditions were used for the polymerase chain reaction: initial denaturation step at $95^{\circ} \mathrm{C}$ for 10 minutes, and 40 cycles of $92^{\circ} \mathrm{C}$ for 15 seconds and $60^{\circ} \mathrm{C}$ for 1 minute. Approximately $10 \%$ of the samples were re-genotyped to ensure reproducibility and accuracy.

\subsection{Statistical analysis}

All statistical analysis was performed using SPSS v.16.0 (SPSS Inc., Chicago, Illinois., USA). The descriptive statistics were determined for all variables and are presented as mean (SD) for the normally distributed variables (or as the median [IQR] for non-normal variables). The chi-square or Fisher's exact tests were applied to evaluate differences in allele and genotype distribution among the examined groups. It was also used to assess any deviation 
from the Hardy-Weinberg equilibrium (HWE) for the study SNP. Independent-samples t-test was used to compare the means of demographic and clinical variables between independent groups. Analyses of variance (ANOVA) followed by the Bonferroni post hoc test, was performed to compare anthropometric traits for differences between genotype groups. Using data from our previous report regarding the other common variant (rs17373080) of LXR $\beta$ gene (17), haplotype frequencies for two sites and any potential relationship with excess weight were estimated using the SNPStats program (18). Logistic regression analyses were used to calculate the odds ratios (ORs) with $95 \%$ confidence interval (CI) of each related parameter, both in crude or adjusted for age and gender. All the analyses were two-sided and statistical significance was set at $\mathrm{p}$-value of $<0.05$.

\section{Results}

\subsection{Characteristics of the Populations}

The baseline characteristics of the total genotyped samples, stratified by BMI status, are presented in Table 1. In total, 168 obese, 209 overweight and 76 normal-weight subjects were successfully genotyped and analyzed. As expected, all people in normal BMI group exhibited a significantly lower level of WC, HC and waist/hip ratio than the two other groups $(\mathrm{p}<0.0001)$. A very strong positive correlation was found between BMI and WC and $\mathrm{HC}$ $(\mathrm{Rho}=0.820 ; \mathrm{p}<0.0001$ and $\mathrm{Rho}=0.771 ; \mathrm{p}<0.0001$ respectively). There were no significant differences in the levels of mean age, serum TC and LDL-C, between the overweight/obese and normal subjects ( $p>0.05$ for all).

Table 1. Demographic and clinical characteristics of the study population

\begin{tabular}{|l|l|l|l|l|}
\hline Characteristics & Normal $(\mathrm{n}=76)$ & Overweight $(\mathrm{n}=209)$ & Obese $(\mathrm{n}=168)$ & $\mathrm{p}$-value \\
\hline Gender $(\mathrm{M} / \mathrm{F})$ & $25 / 51$ & $87 / 122$ & $43 / 125$ & 0.005 \\
\hline Age $($ years $)$ & $48.30 \pm 8.00$ & $47.76 \pm 7.07$ & $48.23 \pm 7.08$ & 0.767 \\
\hline Weight $(\mathrm{kg})$ & $59.42 \pm 7.64$ & $72.33 \pm 9.08$ & $82.54 \pm 10.02$ & 0.001 \\
\hline Height $(\mathrm{cm})$ & $160.37 \pm 9.53$ & $161.72 \pm 8.95$ & $158.58 \pm 8.38$ & 0.003 \\
\hline BMI $\left(\mathrm{kg} / \mathrm{m}^{2}\right)$ & $23.04 \pm 1.57$ & $27.56 \pm 1.37$ & $32.78 \pm 2.65$ & 0.001 \\
\hline Waist circumference $(\mathrm{cm})$ & $83.45 \pm 9.66$ & $92.40 \pm 8.73$ & $102.65 \pm 8.71$ & 0.001 \\
\hline Hip circumference $(\mathrm{cm})$ & $95.16 \pm 5.02$ & $101.48 \pm 4.98$ & $110.67 \pm 7.84$ & 0.001 \\
\hline W/H ratio & $0.88 \pm 0.08$ & $0.91 \pm 0.07$ & $0.93 \pm 0.07$ & 0.001 \\
\hline Glucose $(\mathrm{mmol} / \mathrm{l})$ & $4.49 \pm 0.95$ & $4.65 \pm 0.93$ & $4.89 \pm 1.14$ & 0.009 \\
\hline HDL-C $(\mathrm{mmol} / \mathrm{l})$ & $1.12 \pm 0.28$ & $1.02 \pm 0.21$ & $1.03 \pm 0.21$ & 0.002 \\
\hline LDL-C $(\mathrm{mmol} / \mathrm{l})$ & $3.12 \pm 1.03$ & $3.17 \pm 0.82$ & $3.16 \pm 0.86$ & 0.864 \\
\hline TC $(\mathrm{mmol} / \mathrm{l})$ & $4.74 \pm 1.08$ & $4.96 \pm 1.00$ & $5.05 \pm 0.97$ & 0.085 \\
\hline TG $(\mathrm{mmol} / \mathrm{l})$ & $1.53 \pm 1.11$ & $1.83 \pm 1.11$ & $1.90 \pm 1.08$ & 0.048 \\
\hline SBP $(\mathrm{mmHg})$ & $116.22 \pm 14.41$ & $121.40 \pm 17.06$ & $124.01 \pm 19.30$ & 0.006 \\
\hline DBP $(\mathrm{mmHg})$ & $74.66 \pm 10.90$ & $79.92 \pm 11.01$ & $81.49 \pm 11.13$ & 0.001 \\
\hline
\end{tabular}

BMI, body mass index; SBP, systolic blood pressure; DBP, diastolic blood pressure; W/H, waist/hip; TC, total cholesterol; HDL-C, high density lipoprotein; LDL-C, low density lipoprotein cholesterol; TG, triglycerides. Values were expressed as mean \pm SD.

\subsection{Genotypic and allelic frequencies}

The allelic and genotypic frequencies of the investigated SNP in the entire study group are summarized in Table 2. The distribution of genotypes was in accordance with HWE ( $p>0.05)$. As shown in Table 2, allelic and genotypic associations of LXR $\beta$ rs 2695121 variant were not significant with excess weight. These results maintained statistical insignificancy even after adjustment for gender and age. Additionally, further gender-based association analysis did not modify the results. We also examined association of different genotypes of LXR $\beta$ rs 2695121 with anthropometric and obesity-related metabolic and found no statistically significant differences (Table 3). However, SBP and DBP were significantly higher in subjects with the TC and TT genotypes ( $\mathrm{p}=0.031, \mathrm{p}=0.017$ respectively). Using the data combinations of two SNPs in LXR $\beta$ gene (rs2695121-rs17373080), we then explored the haplotype frequencies and $\mathrm{D}^{\prime}$ and $\mathrm{r}^{2}$ values for degree of linkage disequilibrium (LD) (Table 4). According to the results of haplotype-based analysis associating the two SNPs, three haplotypes including CG, TC, and CC were found to be more common. The overall haplotype frequencies, compared with the most common haplotype (CG), were not statistically different among the studied groups. Haploblock analysis revealed these two SNPs were in strong LD $\left(\mathrm{D}^{\prime}=0.981, \mathrm{r}^{2}=0.518\right.$ in the overweight group and $\mathrm{D}^{\prime}=0.972, \mathrm{r}^{2}=0.550$ in the obese group respectively). 
http://www.ephysician.ir

Table 2. Genotype distributions and Allele frequencies of LXR $\beta$ SNP in the control and overweight/obese groups

\begin{tabular}{|l|l|l|l|l|l|l|l|l|}
\hline \multicolumn{2}{|l|}{ Variables } & Normal & Overweight & Obese & †OR (95\% CI) & p & †OR (95\% CI) & $p$ \\
\hline \multirow{3}{*}{ Genotype } & rs2695121 & 76 & 209 & 168 & Overweight vs. normal & & Obese vs. normal & \\
\cline { 2 - 9 } & CC & $36(47.4)$ & $91(43.5)$ & $69(41.1)$ & & - & & - \\
\cline { 2 - 10 } & CT & $32(42.1)$ & $96(45.9)$ & $81(48.2)$ & 1.00 & 0.546 & 1.00 & 0.914 \\
\cline { 2 - 9 } & TT & $8(10.5)$ & $22(10.5)$ & $18(10.7)$ & $1.19(0.68-2.07)$ & 0.854 & $1.32(0.74-2.35)$ & 0.586 \\
\hline \multirow{2}{*}{ Allele } & C allele & $104(68.4)$ & $278(66.5)$ & $219(65.2)$ & $1.08(0.44-2.66)$ & - & $1.17(0.46-2.91)$ & - \\
\cline { 2 - 9 } & T allele & $48(31.5)$ & $140(33.5)$ & $117(34.8)$ & 1.00 & 0.667 & 1.00 & 0.483 \\
\hline
\end{tabular}

$\mathrm{X}^{2}$-test and Logistic regression were used. OR, odds ratio; CI, confidence interval. $\uparrow$ Adjusted for Age and Sex.

Table 3. Associations of the LXR $\beta$ rs 2695121 variant with anthropometric and metabolic parameters

\begin{tabular}{|c|c|c|c|c|}
\hline \multirow[t]{2}{*}{ Characteristics } & \multicolumn{4}{|l|}{ rs2695121 } \\
\hline & $\mathrm{CC}$ & $\mathrm{CT}$ & TT & $\mathrm{p}$ \\
\hline n (\%) & $197(43.1)$ & $211(46.2)$ & 49 (10.7) & - \\
\hline Weight $(\mathrm{kg})$ & $73.68 \pm 12.07$ & $74.08 \pm 12.26$ & $74.45 \pm 12.26$ & 0.695 \\
\hline Height $(\mathrm{cm})$ & $160.8 \pm 9.3$ & $159.9 \pm 8.7$ & $160.1 \pm 7.7$ & 0.873 \\
\hline BMI $\left(\mathrm{kg} / \mathrm{m}^{2}\right)$ & $28.4 \pm 3.8$ & $28.9 \pm 4.0$ & $29.1 \pm 4.6$ & 0.456 \\
\hline $\mathrm{WC}(\mathrm{cm})$ & $93.7 \pm 11.6$ & $95.6 \pm 10.7$ & $94.7 \pm 11.3$ & 0.184 \\
\hline $\mathrm{HC}(\mathrm{cm})$ & $103.4 \pm 8.2$ & $104.2 \pm 8.4$ & $104.4 \pm 9.6$ & 0.684 \\
\hline $\mathrm{W} / \mathrm{H}$ ratio & $0.91 \pm 0.08$ & $0.92 \pm 0.07$ & $0.91 \pm 0.07$ & 0.147 \\
\hline Glucose $(\mathrm{mmol} / \mathrm{l})$ & $4.69 \pm 0.95$ & $4.75 \pm 1.14$ & $4.53 \pm 0.68$ & 0.337 \\
\hline HDL-C (mmol/l) & $1.02 \pm 0.24$ & $1.05 \pm 0.23$ & $1.08 \pm 0.22$ & 0.282 \\
\hline LDL-C $(\mathrm{mmol} / \mathrm{l})$ & $3.12 \pm 0.90$ & $3.21 \pm 0.85$ & $3.20 \pm 0.66$ & 0.732 \\
\hline $\mathrm{TC}(\mathrm{mmol} / \mathrm{l})$ & $4.89 \pm 1.03$ & $5.00 \pm 1.00$ & $5.02 \pm 0.86$ & 0.628 \\
\hline TG (mmol/l) & $1.79 \pm 1.06$ & $1.79 \pm 1.08$ & $1.85 \pm 1.31$ & 0.918 \\
\hline SBP (mmHg) & $119.7 \pm 17.2$ & $123.3 \pm 18.0$ & $120.7 \pm 17.1$ & 0.031 \\
\hline DBP $(\mathrm{mmHg})$ & $78.4 \pm 11.3$ & $81.2 \pm 10.4$ & $78.2 \pm 13.7$ & 0.017 \\
\hline
\end{tabular}

Values are expressed as mean \pm Sd. Bold values represent significant $p$-value. Adjusted for age and gender.

Table 4. Haplotype frequencies associating LXR $\beta$ rs2695121-rs17373080 polymorphisms in the study population and linkage disequilibrium statistics.

\begin{tabular}{|c|c|c|c|c|c|}
\hline \multirow[t]{2}{*}{ Gene } & \multirow[t]{2}{*}{ Haplotype } & \multicolumn{3}{|c|}{ Frequency } & \multirow[b]{2}{*}{ p-value } \\
\hline & & Controls & Overweight & Obese & \\
\hline \multirow[t]{4}{*}{ LXR $\beta$} & CG & 0.36 & 0.37 & 0.38 & \multirow{4}{*}{0.88} \\
\hline & $\mathrm{TC}$ & 0.32 & 0.31 & 0.34 & \\
\hline & $\mathrm{CC}$ & 0.33 & 0.30 & 0.27 & \\
\hline & TG & 0.006 & 0.00 & 0.004 & \\
\hline \multirow[t]{2}{*}{ LD } & $\mathrm{D}^{\prime}$ & 1.00 & 0.981 & 0.972 & \\
\hline & $\mathrm{r}^{2}$ & 0.502 & 0.518 & 0.550 & \\
\hline
\end{tabular}

The degree of linkage disequilibrium (LD) between the two variants is shown as $\mathrm{D}^{\prime}$ and $\mathrm{r}^{2}$ for each group.

\section{Discussion}

To our knowledge, this study constitutes the first report on the possible association of LXR $\beta$ gene rs2695121 variant with excess weight and obesity-related metabolic traits in an Iranian population. Our results indicated this SNP was not identified as an independent risk factor for obesity. Further, haplotype analysis with another SNP (rs17373080) of the same gene, revealed no significant evidence of relationship with the risk of overweight/obesity or related phenotypes. In all, our results provide evidence that LXR $\beta$ may not be involved in the development of obesity. However, other studies have reported inconsistent data. In particular, in one study conducted by Dahlman and colleagues on Swedish obese women, the two SNPs of the LXR $\beta$ gene including LB44732G>A and rs2695121, were found to be nominally associated with obesity-related phenotypes (13). Nevertheless, consistent with them at the rs2695121 locus, our results showed the CT genotype was more common in overweight/obese groups (48\%) than in the control group (42\%), which implicates an increased risk of susceptibility to excess weight $(\mathrm{OR}=1.32$, $95 \% \mathrm{CI}, 0.74-2.35, \mathrm{p}=0.914)$. In another study by Solaas et al, characterizing the impact of genetic variability of the LXR $\beta$ gene on various metabolic phenotypes in three independent samples, two polymorphisms of LXR $\beta$ 
(rs17373080 and rs2695121) were shown to be associated with insulin and HOMA-IR values in adult subjects in which $\mathrm{G}$ allele of rs 17373080 has been reported as a risk allele for overweight/obesity (14). However, in line with our results, two above mentioned studies reported no association of rs2695121 or rs17373080 with BMI as a continuous trait in their larger samples. Although our results do not support the possible association of LXR $\beta$ gene with increased risk of obesity and related phenotypes, we cannot exclude this possibility for several reasons: first, there is sufficient evidence suggesting that LXRs are critically involved in cholesterol homeostasis, and lipid metabolism (19), and their effect on obesity has also been examined in both human and animal models (20-23). They all indicated a modulatory role for LXRs in many metabolic and inflammatory pathways that are potentially contributing to the development of various metabolic disorder, especially obesity. However, the in vivo contribution of LXR-dependent gene expression in the setting of obesity is still unclear. It is also worth noting that other SNPs located within the same gene without a strong LD with these two polymorphisms (rs17373080, rs2695121) may be associated with the risk of disease development. Second, although rs2695121 genotypes did not show any association with obesity, the CT genotype was associated with SBP and DBP ( $p=0.031$ and $p=0.017$ respectively) as one of the obesity-related metabolic parameters, indicating the possible role of LXR $\beta$ in pathophysiology of obesity. Due to the relatively small sample size, the statistical power of this study may be insufficient to pick up a significant association. It should be noted that, a well-defined sampling strategy with an ethnically homogenous population is one of the main strengths of the present study which avoided possible bias due to individual selection. Finally, if lifestyle factors such as dietary intake and physical activity were taken into account, it might be able to better control the impact of probable confounding factors and compensatory mechanisms, and reveal the subtle effect of LXR $\beta$ on excess weight.

\section{Conclusions}

To our knowledge, this is the first study investigating the role of LXR $\beta$ rs269512 polymorphism with excess weight in an Iranian population. In conclusion, our results can not reveal any association between rs2695121 polymorphism of LXR $\beta$ gene and obesity/overweight except for blood pressure as an obesity-related phenotype. Our negative results should be interpreted in light of the limitations of the study and given the related small sample size. Since existing data is supporting the role of genetic variability of LXR $\beta$ in obesity, further investigations in other larger populations are required to investigate the association of LXR $\beta$ gene polymorphisms, to provide more evidence for the biological role of LXR $\beta$ in etiology of obesity and other metabolic disorders.

\section{Acknowledgments:}

We thank all the participants who agreed to participate in this study. This work has been financially supported by Shahid Beheshti University of Medical Sciences.

\section{Conflict of Interest:}

There is no conflict of interest to be declared.

\section{Authors' contributions:}

All authors contributed to this project and article equally. All authors read and approved the final manuscript.

\section{References:}

1) Apfel R, Benbrook D, Lernhardt E, Ortiz MA, Salbert G, Pfahl M. A novel orphan receptor specific for a subset of thyroid hormone-responsive elements and its interaction with the retinoid/thyroid hormone receptor subfamily. Mol Cell Biol. 1994; 14: 7025-35. doi: 10.1128/MCB.14.10.7025. PMID: 7935418, PMCID: PMC359232.

2) Zelcer $N$, Tontonoz $P$. Liver $X$ receptors as integrators of metabolic and inflammatory signaling. J Clin Invest. 2006; 116: 607-14. doi: 10.1172/JCI27883. PMID: 16511593, PMCID: PMC1386115.

3) Baranowski M. Biological role of liver X receptors. J Physiol Pharmacol. 2008; 59 Suppl 7: 31-55. PMID: 19258656.

4) Willy PJ, Umesono K, Ong ES, Evans RM, Heyman RA, Mangelsdorf DJ. Lxr, a Nuclear Receptor That Defines a Distinct Retinoid Response Pathway. Gene Dev. 1995; 9: 1033-45. doi: 10.1101/gad.9.9.1033. PMID: 7744246.

5) Schultz JR, Tu H, Luk A, Repa JJ, Medina JC, Li LP, et al. Role of LXRs in control of lipogenesis. Gene Dev. 2000; 14: 2831-8. doi: 10.1101/gad.850400. PMID: 11090131, PMCID: PMC317060.

6) Steffensen KR, Gustafsson JA. Putative metabolic effects of the liver x receptor (LXR). Diabetes. 2004; 53: S36-42. doi: 10.2337/diabetes.53.2007.S36. PMID: 14749264. 
7) Tontonoz $\mathrm{P}$, Mangelsdorf DJ. Liver $\mathrm{X}$ receptor signaling pathways in cardiovascular disease. Mol endocrinol. 2003; 17: 985-93. doi: 10.1210/me.2003-0061. PMID: 12690094.

8) Ulven SM, Dalen KT, Gustafsson JA, Nebb HI. LXR is crucial in lipid metabolism. Prostag Leukotr Ess. 2005; 73: 59-63. doi: 10.1016/j.plefa.2005.04.009. PMID: 15913974.

9) Mehrad Majd H, Akhtari j, Ravanshad Y. LXRs: The Key Regulators of Intermediary Metabolism in Metabolic Syndrome. Rev Clin Med. 2017; 4: 87-92.

10) Song C, Kokontis JM, Hiipakka RA, Liao S. Ubiquitous receptor: a receptor that modulates gene activation by retinoic acid and thyroid hormone receptors. Proc Natl Acad Sci U S A. 1994; 91: 10809-13. PMID: 7971966, PMCID: PMC45115.

11) Rooki H, Ghayour-Mobarhan M, Haerian MS, Ebrahimi M, Azimzadeh P, Heidari-Bakavoli A, et al. Lack of association between LXRalpha and LXRbeta gene polymorphisms and prevalence of metabolic syndrome: a case-control study of an Iranian population. Gene. 2013; 532: 288-93. doi: 10.1016/j.gene.2013.09.107. PMID: 24100084.

12) Ketterer C, Mussig K, Machicao F, Stefan N, Fritsche A, Haring HU, et al. Genetic variation within the $\mathrm{NR} 1 \mathrm{H} 2$ gene encoding liver $\mathrm{X}$ receptor beta associates with insulin secretion in subjects at increased risk for type 2 diabetes. J Mol Med (Berl). 2011; 89: 75-81. doi: 10.1007/s00109-010-0687-1. PMID: 21042792.

13) Dahlman I, Nilsson M, Jiao H, Hoffstedt J, Lindgren CM, Humphreys K, et al. Liver X receptor gene polymorphisms and adipose tissue expression levels in obesity. Pharmacogenet Genomics. 2006; 16: 881-9. doi: 10.1097/01.fpc.0000236334.49422.48. PMID: 17108812.

14) Solaas K, Legry V, Retterstol K, Berg PR, Holven KB, Ferrieres J, et al. Suggestive evidence of associations between liver $\mathrm{X}$ receptor beta polymorphisms with type 2 diabetes mellitus and obesity in three cohort studies: HUNT2 (Norway), MONICA (France) and HELENA (Europe). BMC Med Genet. 2010; 11. doi: 10.1186/1471-2350-11-144. PMID: 20939869, PMCID: PMC2958901.

15) Rooki H, Ghayour-Mobarhan M, Pourhosseingholi MA, Azarpazhooh MR, Ebrahimi M, Ferns G, et al. Association of LXRalpha polymorphisms with obesity and obesity-related phenotypes in an Iranian population. Ann Hum Biol. 2014; 41: 214-9. doi: 10.3109/03014460.2013.848936. PMID: 24180251.

16) Rooki H, Haerian MS, Azimzadeh P, Mirhafez R, Ebrahimi M, Ferns G, et al. Associations between C1431T and Pro12Ala variants of PPAR $\gamma$ gene and their haplotypes with susceptibility to metabolic syndrome in an Iranian population. Mol Biol Rep. 2014; 41:3127-33. PMID: 24464185. DOI: 10.1007/s11033-014-3172-z.

17) Rooki H, Ghayour-Mobarhan M, Zali MR. Association of LXR $\beta$ rs 17373080 Polymorphism with Obesity and Obesity-Related Phenotypes in an Iranian population. Iran J Endocrinol Metab. 2014; 15: 443-9.

18) Solé X, Guinó E, Valls J, Iniesta R, Moreno V. SNPStats: a web tool for the analysis of association studies. Bioinformatics. 2006; 22: 1928-9. doi: 10.1093/bioinformatics/btl268. PMID: 16720584.

19) Kalaany NY, Gauthier KC, Zavacki AM, Mammen PP, Kitazume T, Peterson JA, et al. LXRs regulate the balance between fat storage and oxidation. Cell Metab. 2005; 1: 231-44. doi: 10.1016/j.cmet.2005.03.001. PMID: 16054068.

20) Korach-Andre M, Parini P, Larsson L, Arner A, Steffensen KR, Gustafsson JA. Separate and overlapping metabolic functions of LXRalpha and LXRbeta in C57Bl/6 female mice. Am J Physiol Endocrinol Metab. 2010; 298: E167-78. doi: 10.1152/ajpendo.00184.2009. PMID: 19690071.

21) Beaven SW, Matveyenko A, Wroblewski K, Chao L, Wilpitz D, Hsu TW, et al. Reciprocal regulation of hepatic and adipose lipogenesis by liver X receptors in obesity and insulin resistance. Cell Metab. 2013; 18: 106-17. doi: 10.1016/j.cmet.2013.04.021. PMID: 23823481, PMCID: PMC4089509.

22) Stulnig TM, Steffensen KR, Gao H, Reimers M, Dahlman-Wright K, Schuster GU, et al. Novel roles of liver X receptors exposed by gene expression profiling in liver and adipose tissue. Mol Pharmacol. 2002; 62: 1299-305. doi: 10.1124/mol.62.6.1299. PMID: 12435796.

23) Cannon MV, van Gilst WH, de Boer RA. Emerging role of liver X receptors in cardiac pathophysiology and heart failure. Basic Res Cardiol. 2016; 111: 3. doi: 10.1007/s00395-015-0520-7. PMID: 26611207, PMCID: PMC4661180. 